\title{
NGNP Site Selection Status Report
}

\author{
December 2006
}

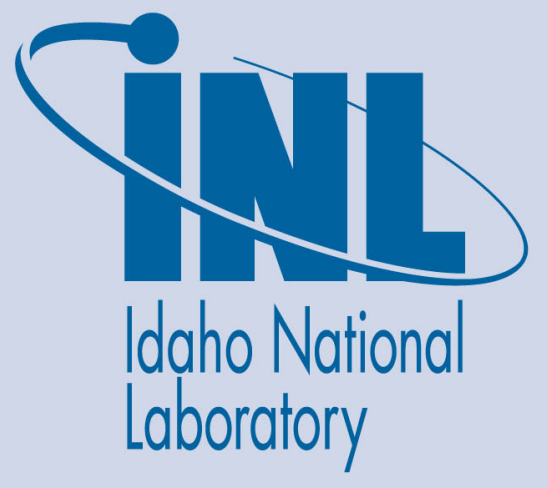

The INL is a U.S. Department of Energy National Laboratory operated by Battelle Energy Alliance 
INL/EXT-12-25795

\title{
NGNP Site Selection Status Report
}

December 2006

\section{Idaho National Laboratory \\ Idaho Falls, Idaho 83415}

http://www.inl.gov

\author{
Prepared for the \\ U.S. Department of Energy \\ Office of Nuclear Energy \\ Under DOE Idaho Operations Office \\ Contract DE-AC07-05ID14517
}




\title{
NGNP SITE SELECTION STATUS REPORT
}

\author{
December 03, 2006
}

\section{Background}

The Energy Policy Act of 2005 (Title VI, Subtitle C, Section 644) states that the "Nuclear Regulatory Commission shall have licensing and regulatory authority for any reactor authorized under this subtitle." This stipulates that the Nuclear Regulatory Commission (NRC) will license the Next Generation Nuclear Plant (NGNP) for operation, which is consistent with the Energy Reorganization Act of 1974 that assigns the responsibility for licensing new Department of Fnergy (DOE) reactors to the NRC if they are used to generate power for an electric utility system or operated in any manner to demonstrate the suitability for subsequent use by the commercial power industry.

The NRC NLPA Regulations (10 CFR Part 51) require that the NRC prepare an Environmental Impact Statement (EIS) for a permit to construct a nuclear power reactor. The applicant is required to submit an Environmental Report (ER) to aid the NRC in complying with NEPA, and the NRC is responsible for evaluating the reliability of any of the information that it uses to prepare the EIS.

This report provides an overview of the NRC licensing process, the preliminary site activities that have taken place in the current fiscal year (FY-06), and the site-related plans for FY-07.

\section{NRC LICENSING PROCESS}

The NRC maintains oversight of the construction and operation of a facility throughout its lifetime to assure compliancc with the Commission's regulations for the protection of public health and safety, the common defense and security, and the environment. To implement this process, all nuclear power plant applications must undergo a safely review, an environmental review, and antitrust review by the NRC.

The following elements of the 10 CFR Part 50 licensing process address the site selection and characterization activities that must be developed to support NGNP licensing.

\section{Construction Permit (CP)}

An application for a Construction Permit (CP) must contain four types of information:

1. Preliminary safety analyses,

2. An environmental review,

3. Financial and antitrust statements, and

4. Assessment of the need for the power plant.

The CP application includes a Preliminary Safety Analysis Report (PSAR). This document contains the design information and criteria for the proposed reactor and comprehensive data on the proposed site. It also discusses various hypothetical accident situations and the safety features of the plant that prevents accidents or, if accidents should occur, lessens their effects. In addition, the application must contain a comprehensive assessment of the environmental impacts and information for antitrust reviews of the proposed plant. 


\section{Site Technical Review}

The NRC staff then reviews the application to determine whether the plant design meets all applicable regulations (10 CFR Parts 20,50,73, and 100). The review includes, in part:

- Characteristics of the site, including surrounding population, seismology, meteorology, geology and hydrology,

- Design of the nuclear plant,

- Anticipated response of the plant to hypothetical accidents,

- Plant operations including the applicant's technical qualifications to operate the plant,

- Discharges from the plant into the environment (i.e., radiological effluents), and

- Emergency plans.

When the NRC completes its review, it prepares a Safety Evaluation Report (SER) summarizing the anticipated effect of the proposed facility on public health and safcty.

\section{NEPA Review}

The NRC NEPA Regulations, at 10 CFR Part 51, require that the NRC prepare an Environmental Impact Statement (EIS) for a permit to construct a nuclear power reactor. The permit applicant is required to submit an ER to aid the NRC in complying with NEPA, and the NRC is responsible for evaluating the reliability of any of the information that it uses to prepare the EIS. After completing this review, the NRC issues a Draft Environmental Impact Statement (EIS) for comment by the appropriate Federal, State, and local agencies as well as by the public. Afterwards, the agency issues a Final EIS that addresses all comments received.

The ER includes an analysis that considers and balances the environmental effects of the proposed action, the environmental impacts of alternatives to the proposed action, and alternatives available for reducing or avoiding adverse environmental effects. The analysis in the ER will also include consideration of the economic, technical, and other benefits and costs of the proposed action and of alternatives, and will contain sufficient data to aid the NRC in its development of an independent analysis.

\section{Potential Use of 10 CFR Part 52}

A potential alternative NEPA/licensing approach may be $t u$ use the provisions of 10 CFR 52, Early Site Permits (ESP). For an ESP, INL would prepare a comprehensive ER, as for a CP, with the exception that the ER would use bounding generic information about maximum impacts based on the reactor type and size. Other environmental information would be essentially the same as for a CP, with the exception that in an early site environmental report, economic benefit of the project does not have to be addressed. The NRC would evaluate the ER and prepare and publish an EIS and Record of Decision. Following this, the NRC would issue an ESP.

An ESP allows the applicant to conduct site preparation, installation of temporary construction support facilities, excavation for facility structures, construction of service facilities, and construction of structures, systems and components that do not prevent or mitigate the consequences of postulated accidents (i.e., non safety-related equipment). However, a $\mathrm{CP}$ would still be required to continue with construction past the site preparations allowed by the ESP. The application for the CP would include an ER that provides all the necessary environmental information not previously addressed. This would then be evaluated by NRC, and the EIS would be supplemented as necessary. 


\section{Operating License (OL)}

After a CP is issued, the applicant must, if it did not as part of the original application, submit a Final Safety Analysis Report (FSAR) to support its application for an Operating License (OL). This report describes the final design of the facility as well as its operational and emergency procedures. The NRC prepares a Final SER for the operating license, and the ACRS makes an independent evaluation and presents its advice to the Commission.

\section{PRELIMINARY SITE ACTIVITIES}

In 1983, a site selection was performed by the DOE for the New Production Reactor (NPR) at the INL. In 1989 , the original site selection process was reviewed to determine if the primary site selected in 1983 was still considered the best site in light of the most recent site characterization data (see Report EGGNPR-8517, Rev. 1, "Site Selection Report for the New Production Reactor at the Idaho National Engineering Laboratory," dated July 1989).

This report determined that there was no reason to alter the previously selected primary location (called "Site E") for the NPR. It is important to note that this activity was taken with the understanding that suitability would be based on NRC siting criteria. Site E is close to established roads, the railroad, and the INL site electrical transmission loop. Considerable resources were expended in characterizing the selected site that is located east of the INTEC facility. Given the type of facility that planned, it is logical that Site E would be a prime candidate for locating the NGNP facility.

Based on the work that was done in the 1980s, it would be cost beneficial to gather any existing data from the NPR effort and not redo the site characterization activities. However, much of that data is currently controlled by the Idaho Cleanup Project (ICP). Therefore, activities have been initiated to determine the location of existing NPR site characterization data.

\section{NPR Site Data Identification}

At this time, NPR-related documents have been identified in the following areas:

- INL Record Storage Facility (IF 663)

- Rescarch Office Building (ROB)

- Technical Support Building (TSB)

Until early 2005, results of the NPR studies and the supporting data were housed in the Hydro-geological Data Warehouse in the ROB building. After the INL contract split, responsibility for the data fell to CWI. At this point, CWI personnel began to move hard copies and electronic records under their control and specific NPR documents ended up in a variety of locations.

The contents of 505 boxes of archived NPR-related documents with were reviewed as part of an effort to retrieve background data and documentation to support the NGNP project. These boxes are currently maintained at the INL Record Storage Facility. In addition, well logs, maps of archaeological surveys, and well and borehole locations for Site E (and NPR alternate Site A) were found in the ROB.

The CWI Spatial Arralysis Lab in TSB maintains the Environmental Data Warchouse (EDW). This electronic data application can be accessed via the web to view well log data and other environmental data for the INL. The original well logs and associated data are kept in a locked room (vault) in the TSB. Efforts should be made to assess the completeness of the original logs and/or actually view the logs for key wells/bore holes of interest. Project personnel are beginning those efforts. 
Efforts will continue to identify any additional locations that may contain NPR-related documents that could be applicable to address future siting issues.

\section{Site Characterization Data Separation}

A large number of boxes containing NPR-related documents have becn identificd at the locations noted above. However, a large percentage of these documents are design-related and are not useful for addressing the siting issues. Therefore, these boxes will need to be screened to separate out the boxes that contain site characterization documents. Screening will be performed as follows:

- A sample of boxes will be identified and the contents will be inventoried and compared to the box inventory sheet. This process will provide a basis for relying on the existing inventory sheets as the basis for identifying boxes that contain site characterization data.

- The list of the materials in each box will be scanned in and put on EDMS for electronic searches. Once it is known what specific information is needed, those lists can be searched and personnel can go back to the specific boxes for potentially useful documents.

- NPR-related documents found in other locations (e.g., ROB and TSB) will need to be inventoried by hand to separate out documents of interest.

\section{Storage}

Once documents of interest are identified, they will be moved to a separate storage location where they

can be easily accessed and controlled. No long-term location has been identified at this time. However, a number of lockable cabinets have been identified that can be used to handle the smaller volume documents located outside the Record Storage Facility. Applicable documents that are currently located in the Records Storage Facility may be left at that facility until an appropriate limited access storage location is procured.

The holding time for all of the NPR-related documents currently stored in the Record Storage Facility will be extended to ensure that no records are inadvertently moved to another location.

The project must identify where to organize and control our project records (over the long term) that will be needed to support the NRC licensing process. The space needed and the control requirements that must be applied to mect NQA-1 are not trivial. Initial inquiries have found that the laboratory resources for a large controlled library are scarce. This issue will require management attention.

\section{ENVIRONMENTAL REPORT DEVELOPMENT}

Prior to issuing a construction permit or an operating license for a nuclear power facility, the NRC must assess the potential impacts that the facility may have on the environment. This is to ensure that the following NEPA goals are met:

1. Fulfill the responsibilities of each generation as trustee of the environment for succeeding generations;

2. Assure for all Americans safe, healthful, productive, and aesthetically and culturally pleasing surroundings;

3. Attain the widest range of beneficial uses of the environment without degradation, risk to health or safety, or other undesirable and unintended consequences;

4. Preserve important historic, cultural, and natural aspects of national heritage, and maintain, wherever possible, an environment which supports diversity and variety of individual choice; 
5. Achieve a balance between population and resource use which will permit high standards of living and wide sharing of life's amenities; and

6. Enhance the quality of renewable resources and approach the maximum attainable recycling of depletable resources.

In order to obtain information that is needed for this assessment, the NRC requires an applicant to develop an ER that delineates the potential impacts that the proposed facility may have on the environment.

Sections 51.50 and 51.53 of 10 CFR Part 51 require that applicant to submit two ERs. The first is for the "Construction Permit Stage," which is submitted with the construction permit application. The second, "Operating License Stage," is submitted later with the operating license application. 'Thus, the initial focus for the NGNP project will be on developing the construction permit ER.

\section{Environmental Report Contents}

The contents for an ER are specified in 10 CFR 51.30. The ER contains a description of the proposed action, a statement of its purposes, and a description of the environment affected, and discusses the following considerations:

- The impact of the proposed action on the environment, discussed in proportion to their significance.

- Any adverse environmental effects that cannot be avoided should the proposal be implemented.

- Alternatives to the proposed action. The discussion of alternatives must be sufficiently complete to aid the NRC in developing and exploring, pursuant to section 102(2)(E) of NEPA, "appropriate alternatives to recommended courses of action in any proposal which involves unresolved conflicts concerning alternative uses of available resources." To the extent possible, the environmental impacts of the proposal and the alternatives should be presented in comparative form.

- The relationship between local short-term uses of man's environment and the maintenance and enhancement of long-term productivity.

- Any irreversible and irretrievable commitments of resources that would be involved in the proposed action should it be implemented.

The following subsections cover the ER organization and content, including a description of the various types of environmental data that must be gathered in advance to support development of the ER. The basis for this information is found in NRC Regulatory Guide 4.2, Rev 2, "Preparation of Environmental Reports for Nuclear Power Stations," dated July 1976.

\section{Chapter 1 - Purpose of Proposed Facility}

This first chapter of the ER documents the purpose and the benefits of the NGNP with respect to the power requirements to be satisfied, the system reliability to be achieved, and any other primary objcctives for the facility. Given the uniqueness of the NGNP and its associated hydrogen/process heat generation capabilities, this first chapter will contain descriptive information that differs significantly from a typical commercial power plant proposal.

\section{Chapter 2 - Site and Environmental Interfaces}

This chapter contains the applicable information related to the physical, biological, and human characteristics of the site's environment that could be affected by the construction and operation of the 
NGNP facility. This includes a discussion of the geography and demography of the site and surrounding area. Other types of data presented in this chapter include the following:

- Ecology - Describe the flora and fauna in the vicinity of the site, their habitats, and their distribution. Establish the identity of the majority of terrestrial and aquatic organisms on or near the site and their relative abundances. Identify any definlable preexisting environmental stresses from sources such as pollutants. Information should be presented in two separate subsections ("Terrestrial Ecology" and "Aquatic Ecology").

- Meteorology - Provide a meteorological description of the NGNP site and its surrounding area. Include the use of at least one annual cycle from the onsite meteorological program for a construction permit application and at least two annual cycles, including the most recent 1 -year period for an operating license application.

- Hydrology - Describe, in qualitative terms, the physical, chemical, biological, and hydrological characteristics, the typical seasonal ranges and averages, and the historical extremes for surface and ground water bodies. Information is needed only for those waters that may affect station effluents and water supply or that may be assumed to be affected by the construction or operation of the NGNP facility. For those water bodies and systems that may receive radionuclides from the NGNP facility, the data should be supplied out to a 50 mile radius from the facility.

- Geology - Describe the major geological aspects of the site and its immediate environs. Except for those specific features that are relevant to the environmental impact assessment, the discussion may be limited to noting the broad features and general characteristics of the site and environs (i.e., topography, stratigraphy, and soil and rock types).

- Historic, Archeological, Architectural, Scenic, Cultural, and Natural Features - The ER should include a brief discussion of the significance of any of these issues relative to the NGNP site, with specific attention to the sites and areas listed in the Natural Registry of Natural Landmarks and properties included in or eligible for inclusion in the National Register of Historic Places.

- Noise - Ambient noise levels obtained from the surrounding biotic communities within five miles of the NGNP site location should be reported. Particular attention should be directed toward obtaining acoustic noise levels where high voltage transmission lines are located.

\section{Chapter 3 - The Station}

The NGNP facility and the transmission system are described in this chapter. Since environmental effects are of particular interest in the ER, NGNP effluents and other facility systems that interact with the environment should be described in detail. Depending on the timing of the completion of the NGNP design, this chapter could present a real challenge. Detailed system knowledge will be required to estimate and identify the radioactive source terms and chemical effluents that will result from the NGNP facility. Therefore, development of a NGNP-applicable plant parameter envelop (PPE) may be necessary if adequate design information is not available during preparation of the construction permit ER. Some issues may also be resolved in the Final ER provided during the Operating License Stage.

\section{Chapter 4 - Environmental Effects of Site Preparation and Construction}

This chapter should discuss the expected effects of site preparation, and NGNP and transmission facility construction. The effects are to be presented in terms of the impact on the resources and populations described in Chapter 2. Methods used to determine these impacts should be described.

\section{Chapter 5 - Environmental Effects of Station Operation}


This chapter is intended to describe the interaction of the NGNP facility (discussed in Chapter 3) and the environment (discussed in Chapter 2). Planned actions to reduce undesirable effects caused by NGNP operation should be described in detail. Effects that are temporary or subject to later amelioration should be distinguished from other effects that are unavoidable and irreversible.

\section{Chapter 6 - Effluent and Environmental Measurements and Monitoring Programs}

The means by which baseline data presented in the other chapters should be described in this chapter. This description should include plans and programs for monitoring the environmental impacts of NGNP site preparation, facility construction, and NGNP operation.

\section{Chapter 7 - Environmental Effects of Accidents}

This chaptcr should discuss the potential environmental effects of accidents involving the NGNP facility. This discussion should include accidents involving radioactivity, chemical explosions, fires, and oil or toxic material spills.

\section{Chapter 8 - Economic and Social Effects of Construction and Operation}

This chapter should describe our assessment of the economic and social effects of the NGNP facility. Given the difficult task of accurately assessing the economic benefits and costs related to operation of a facility over a long period of time, this assessment should focus on those benefits and costs that are measurable, such as the generated electricity and the capital, operating, and maintenance costs.

\section{Chapter 9 - Alternative Energy Sources and Sites}

The basis for the NGNP site selection should be documented in this chapter. Normally, this chapter would discuss the range of alternatives and the rationale that led to selection of the site and the choice of nuclear power as the selected energy source. However, the directed research and development mission of the NGNP project may require us to be creative as we develop this chapter. 


\section{Chapter 10 - Station Design Alternatives}

This chapter should describe how the NGNP project arrived at the facility design through consideration of alternative designs for systems.

\section{Chapter 11 - Summary Cost-Benefit Analysis}

The NGNP project should develop an analysis that demonstrates that the total benefits outweigh the total costs.

\section{Chapter 12 - Environmental Approvals and Consultation}

This chapter should list all Federal permits, licenses, approvals, and other entitlements that must be obtained and describe the status of compliance with these requirements. The ER should also include a discussion of the status of compliance with applicable environmental quality standards and requirements including, but not limited to, applicable zoning and land-use regulations, and thermal and other water pollution limitations or requirements that have been imposed by federal, state, regional, and local agencies having responsibility for environmental protection.

\section{Chapter 13 - References}

This chapter provides a bibliography of the sources used in preparation of the ER. 


\section{Environmental Review Process}

The following figure lays out the overall process for ER development, submittal as part of the construction permit, and the NRC staf؟'s subsequent development of the EIS.

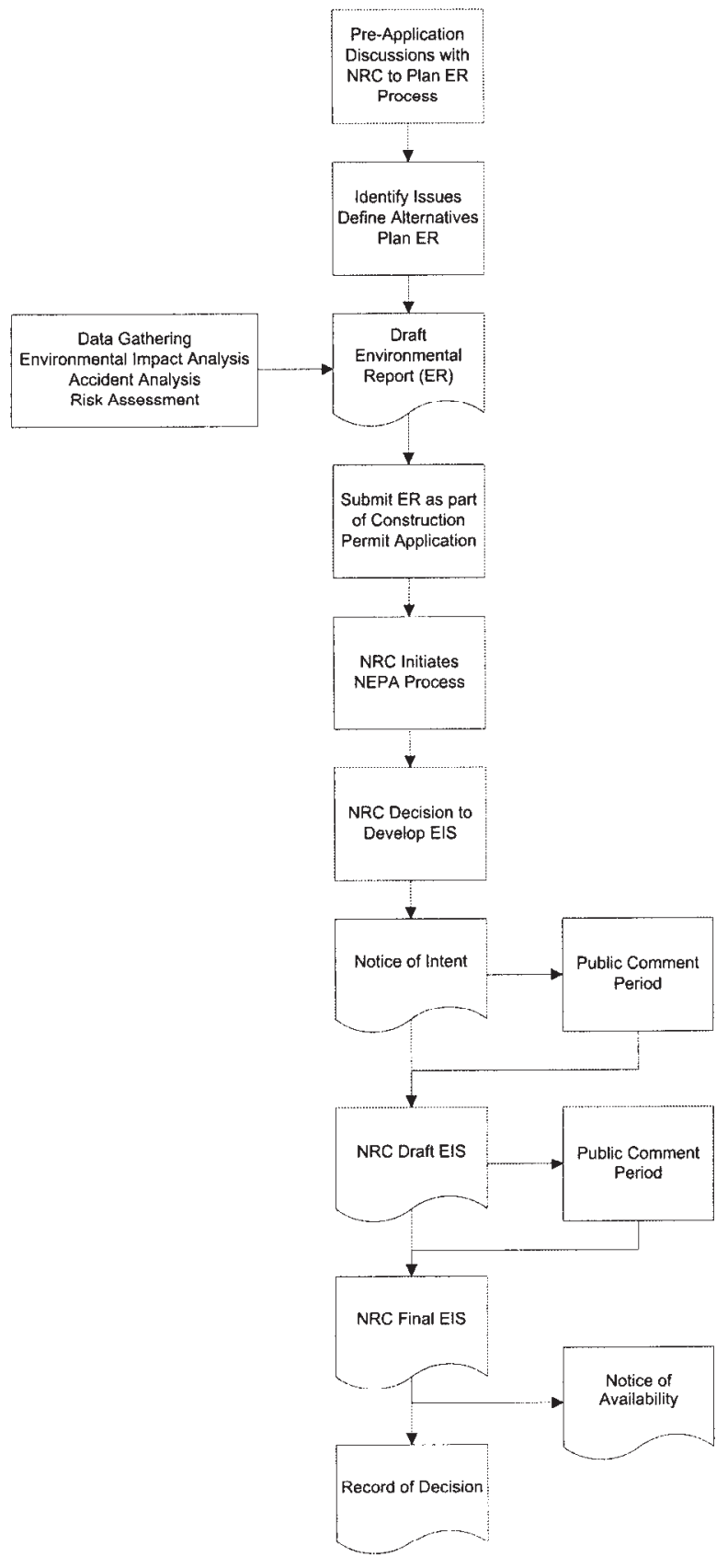

Figure 3-1 Environmental Report Review Process

Key points associated with Figure 3-1 include the following:

- In the case of the NGNP, the decision to prepare the ER will be initiated once the site location has been selected. There are independent engineering studies commencing that will look at the existing rationale for using NPR Site E and will provide some recommendations by the end of FY-07. 
- The NGNP project is responsible for identifying issues, defining alternatives, planning the ER development, gathering the necessary data, and performing the various analyses and risk assessments. It is expected that some of this work will be performed by subcontractors.

- Once the ER is completed and submitted to the NRC as part of the construction permit, the NRC takes over and uses the ER as a reference for their EIS development and assessment. This EIS is then made available to the public and comments are incorporated into the final EIS and a record of decision is issued.

- As noted earlier, some issucs may not be fully addressed at the Construction Permit Stage. These issues are carried over and are resolved during the Operating License Stage after the necessary information is available and evaluated.

\section{Environmental Report Development Schedule}

The following figure lays out the current schcdule for development of the site characterization data and the eventual ER. This activity assumes that the NPR Site E will become the preferred location for the NGNP. However, as noted above, separale engineering studies will occur to evaluatc the suitability of Site $E$ for our purposes. In any case, understanding the usefulness of existing NPR Site E data will be critical to the site selection decision-making process.

The FY-07 level $2 \& 3$ deliverables contained in Work Package G-IN07NG0802 (NGNP Site Selection and Characterization) are included in this schedule (see next Section 4 for more FY-07 detail).

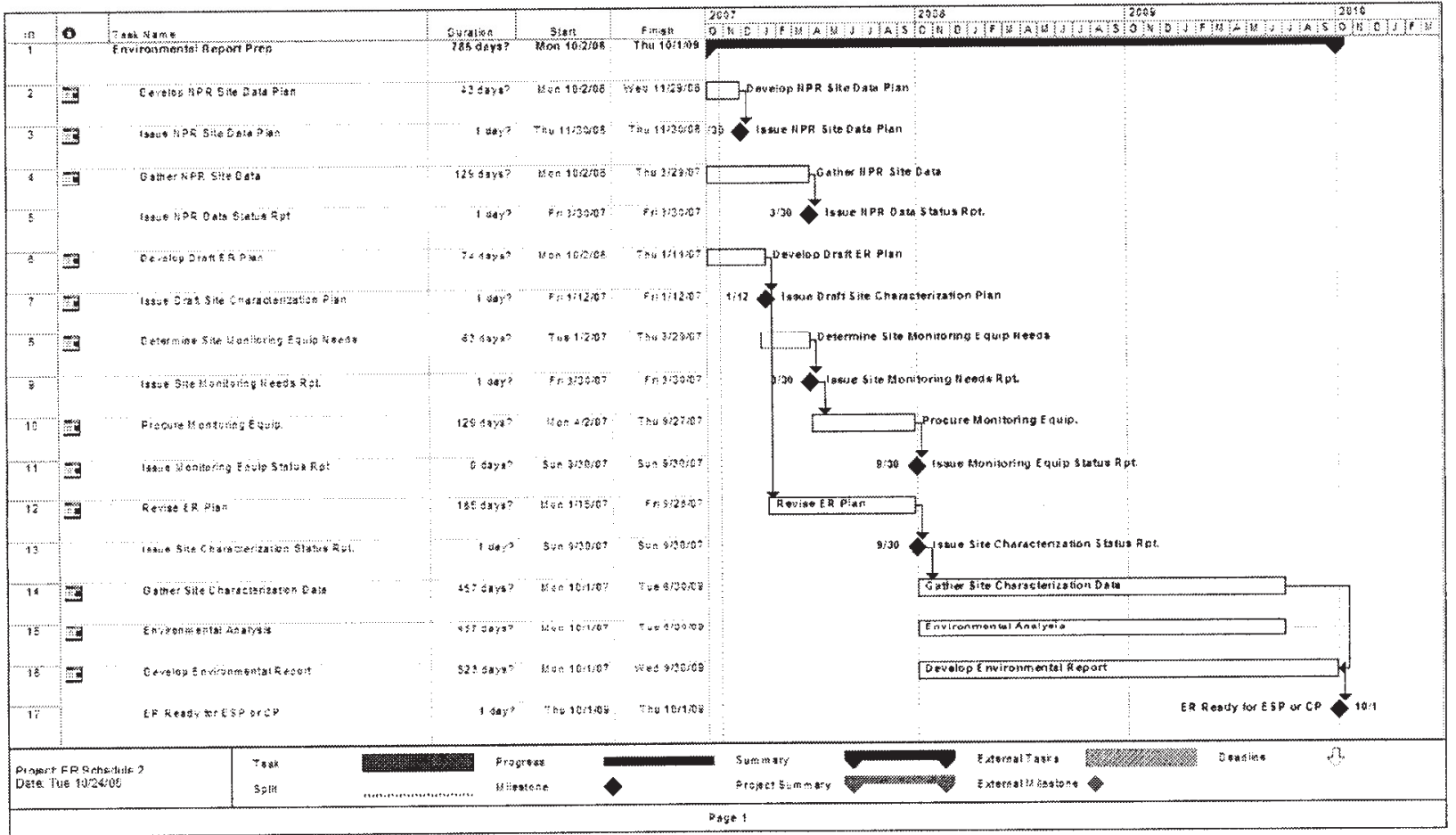

\section{Notes:}

- This schedule supports the NGNP Preliminary Project Management Plan's Option 2 time line that specifies submission of an NRC Construction Permit application in the FY-10 timeframe. 
- The task breakdown and durations for FY-08 and FY-09 may need revision once the NGNP integrated schedule is completed. These work activities will be refined as the public/private partnership is developed and as the NRC licensing strategy is finalized.

- The effect of the continuing resolution budgetary process will directly determine our ability to complete some of the FY-07 activities. For example, it is doubtful that site monitoring equipment would be procured if the continuing resolution persists beyond February 2007.

\section{FY-07 SITE SELECTION AND CHARACTERIZATION TASKS}

It is anticipated that the following site-related tasks will be initiated in FY-07. This work has been identified in Work Package G-IN07NG0802. In general, this work package addresses the initial work needed to gather cxisting characterization data that was developed during the NPR project. This includes identifying new activities needed to develop an environmental report and meet current licensing requirements.

Once the existing data is gathered, it will be evaluated to ensure that the site is still acceptable in today's regulatory environment. Work activities needed to update or add additional supporting data will be identified.

The FY-07 work tasks are summarized below:

- Develop plan to gather existing NPR site data,

- Gather existing NPR site data,

- Develop site selection/characterization plan,

- Identify site monitoring needs,

- Procure monitoring equipment, and

- Develop site selection/characterization status report.

Deliverables associated with this work package will include:

- Level 2 - Develop draft plant for site selection and characterization (January 12, 2007). A revision of this report will form the basis of this deliverable.

- Level 3 - Complete site selection and characterization status report (September 30,2007)

If you have any questions regarding information contained in this report, please contact Mark Holbrook, NGNP Licensing Coordinator, by telephone at 208-526-4362, or e-IIlail at Inark.holbrook@inl.gov. 